\title{
PENGARUH LAYANAN BIMBINGAN KELOMPOK TERHADAP KONFORMITAS TEMAN SEBAYA
}

\author{
Mulia Sartika ${ }^{1}$, Hengki Yandri ${ }^{2}$ \\ 1, 2 Institut Agama Islam Negeri (LAIN) Kerinci \\ e-mail: hengki@konselor.org
}

\begin{abstract}
This research is motivated by the phenomenon of negative student peer conformity. The purpose of this study was to explain the effect of group guidance services on peer conformity through an experimental approach with the design of the one group pretest-posttest design. The research sample was 10 people selected through purposive sampling technique. Data was revealed through a Likert scale model questionnaire and analyzed using the Wilcoxon Signed Ranks Test. The results showed that there was a significant effect on peer conformity in students after being given treatment in the form of group guidance services.
\end{abstract}

Keywords: Group Guidance, Conformity, Peer Friends.

\begin{abstract}
Abstrak. Penelitian ini dilatarbelakangi oleh fenomena masih adanya konformitas teman sebaya siswa yang negatif. Tujuan penelitian ini untuk menjelaskan pengaruh layanan bimbingan kelompok terhadap konformitas teman sebaya melalui pendekatan eksperimen dengan rancangan the one group pretest-posttest design. Sampel penelitian sebanyak 10 orang yang dipilih melalui teknik purposive sampling. Data diungkap melalui angket model skala likert dan dianalisis menggunakan uji Wilcoxon Signed Ranks Test. Hasil penelitian menunjukkan bahwa terdapat pengaruh yang signifikan terhadap konformitas teman sebaya pada siswa setelah diberikan perlakuan berupa layanan bimbingan kelompok.
\end{abstract}

Kata Kunci: Bimbingan Kelompok, Konformitas, Teman Sebaya.

\section{PENDAHULUAN}

Hubungan sosial individu berkembang karena adanya dorongan rasa ingin tahu terhadap segala sesuatu yang ada didunia sekitarnya. Dalam perkembangannya, setiap individu ingin tahu bagaimanakah cara melakukan hubungan secara baik dan aman dengan dunia sekitarnya, namun kebanyakan individu sekarang banyak yang berperilaku buruk, baik secara fisik maupun sosial. Hubungan sosial diartikan sebagai cara-cara individu berinteraksi dengan orang-orang di sekitarnya. Hubungan sosial ini dimulai dari rumah, dilanjut dengan teman 
sebaya, baru dengan teman-temannya di sekolah. Sehingga hubungan sosial pada remaja sangat kuat sekali, masa remaja merupakan salah satu periode dalam rentangan kehidupan manusia (Alisyahban, dkk dalam Ali dan Asrori, 2014). Dalam masa remaja ini individu mengalami banyak tantangan perkembangannya, baik dalam diri maupun luar diri terutama lingkungan sosial (Elida, 2006).

Perkembangan remaja merupakan masa transisi dari kanak-kanak menuju dewasa. Dalam perkembangan sosial remaja ada dua macam, yaitu memisahkan diri dari orang tua dan yang lain adalah menuju teman sebaya. Menurut Erikson dalam masa remaja, remaja berusaha untuk melepas diri dari orang tua dengan maksud untuk menemukan dirinya, proses ini dinamai dengan proses mencari identitas ego. Awalnya para remaja harus cepat untuk menyesuaikan dirinya pada lingkungan sekitarnya seperti lingkungan sekolah dan teman sebaya. Tidak kalah penting adalah penyesuaian diri dengan meningkatkan pengaruh kelompok sebaya, perubahan dalam perilaku sosial, pengelompokkan sosial yang baru, nilai-nilai baru dalam dukungan dan penolakan sosial. Karena pengaruh lingkungan sosial yang kuat membuat remaja tidak bisa mengendalikan dirinya Rahmayanthi, 2017).

Dikatakan bahwa pengaruhnya kuat karena remaja lebih banyak melakukan aktivitas di luar rumah bersama teman sebayanya yang dianggap sebagai kelompok bermainnya. Remaja lebih merasa senang membentuk-bentuk kelompok seperti komunitas-komunitas tertentu yang dibentuk berdasarkan kesamaan hobi seperti komunitas anak motor, komunitas anak pencipta alam, komunitas brandal dan lain sebagainya sehingga mereka merasa senasip atau sama dalam berperilaku. Padahal dalam kelompok yang seperti itu memiliki aturan atau norma sendiri yang harus dipatuhi oleh setiap individu yang telah masuk dalam kelompok tersebut, maka dari itu setiap remaja atau individu harus menyesuaikan diri pada kelompok tersebut agar mendapat pengakuan dari kelompok atas apa yang dilakukannya. Perubahan perilaku atau keyakinan karena adanya tekanan dari kelompok, baik yang sungguh-sungguh ada maupun yang dibayangkan saja, ini yang disebut dengan konformitas (Kiesler dalam Novianti dan Putra, 2014).

Konformitas adalah orang atau organisasi yang berusaha agar pihak lain menampilkan tindakan tertentu pada saat pihak lain tersebut tidak ingin melakukannya (David, dkk dalam Sear dan Jonathan, 1985). Bila seseorang menampilkan perilaku tertentu karena setiap orang lain menampilkan perilaku tersebut. Dalam Kamus Besar Bahasa Indonesia (2002) menyatakan bahwa konformitas adalah kesesuaian sikap dan perilaku dengan nilai dan kaidah yang berlaku. Banyak remaja beranggapan jika berpenampilan dan berperilaku mengikuti anggota kelompok popular maka kesempatan untuk dapat diterima dalam kelompok popular tersebut lebih besar. 
Sedangkan menurut Baron, Branscombe, Byrne, konformitas adalah suatu bentuk pengaruh sosial dimana individu mengubah sikap dan tingkah lakunya agar sesuai dengan norma sosial. Norma sosial dapat berupa injuctive norms, hal yang harusnya kita lakukan atau descriptive norms, yaitu apa yang kebanyakan orang lakukan. Injuctive norms biasanya dinyatakan secara eksplisit (tegas), misalnya di dalam sebuah kelompok individu harus menggunakan pakaian tidak rapi. Descriptive norms biasanya bersifat implicit (tidak dinyatakan tegas), misalnya menghormati orang tua dengan bersikap sopan (Sarwono dan Eko, 2011).

Konformitas teman sebaya mempunyai pengaruh yang kuat terhadap tingkah laku remaja. Tekanan untuk melakukan konformitas bermula dari adanya aturan-aturan yang telah disepakati bersama dalam kelompok, baik yang tertulis maupun tidak tertulis, yang memaksa individu bertingkah laku yang seharusnya atau yang semestinya (Baron dan Byrne dalam Sarwono dan Eko, 2011). Konformitas terhadap teman sebaya akan menyebabkan remaja mencari informasi tentang kelompoknya dengan tujuan agar individu berperilaku sesuai dengan norma kelompoknya. Dari kelompok teman sebaya individu menerima umpan balik mengenai kemampuannya. Individu belajar tentang apakah yang mereka lakukan lebih baik, sama baik, atau lebih buruk dari apa yang dilakuakan anggota lainnya.

Konformitas teman sebaya juga terjadi di sekolah-sekolah, seperti informasi dari guru bimbingan dan konseling serta guru bidang studi pada bulan Agustus 2017 serta hasil observasi pada kelas X di Sekolah Menengah Atas Negeri (SMAN) 5 Kerinci menunjukkan masih adanya indikasi terjadinya konformitas teman sebaya yang negatif, seperti adanya siswa yang bolos waktu jam pelajaran yang diajak oleh teman, mem-bully temannya yang tidak bisa menjawab pertanyaan dari guru, terdapat juga siswa yang merokok diwaktu jam istirahat karena teman, tidak memakai atribut sekolah dengan lengkap karena ajakan teman. Padahal perilaku yang menyimpang ini tidak sesuai dengan norma sekolah, tetapi tetap saja dilakukan oleh individu untuk mendapatkan penghargaan dari kelompoknya. Kemudian hasil penelitian yang dilakukan oleh Mayara, Yuniarrahmah, dan Mayangsari (2016) menjukkan bahwa konformitas teman sebaya terjadi karena remaja kurang percaya dirinya.

Berdasarkan fenomena ini, menggugah peneliti untuk membantu siswa kelas X dalam mengatasi terjadinya konformitas teman sebaya dengan memanfaatkan layanan bimbingan dan konseling. Bimbingan dan konseling adalah salah satu komponen sekolah yang mengembangkan tugas pendidikan. Bimbingan dan konseling merupakan proses bantuan yang diberikan oleh konselor kepada konseli secara kontinu agar mereka memperoleh konsep diri dalam memperbaiki tingkah lakunya kearah yang lebih baik. Tujuan memberikan layanan bimbingan dan konseling, yaitu agar konseling mengembangkan kepribadiannya sesuai dengan 
potensi-potensi yang dimilikinya secara optimal, bertanggungjawab atas keputusan dan arah hidupnya. Dengan berbagai jenis layanan yang ada dalam bimbingan dan konseling yang diterapkan di sekolah, layanan yang paling tepat digunakan melihat dari fenomena yang ada salah satunya adalah layanan bimbingan kelompok.

Bimbingan kelompok merupakan suatu cara memberikan bantuan atau bimbingan kepada individu atau siswa melalui kegiatan kelompok. Dalam layanan bimbingan kelompok, aktivitas, dan dinamika kelompok harus diwujudkan untuk membahas berbagai hal yang berguna untuk pengembangan atau pemecahan masalah individu yang menjadi peserta layanan (Tohirin, 2011). Tujuan layanan bimbingan kelompok yaitu untuk pengembangan kemampuan bersosialisasi khususnya kemampuan berkomunikasi peserta layanan serta dapat mendorong mendorong pengembangan nilai rasa, pemikiran, persepsi, wawasan dan pengetahuan, dan serta sikap untuk mewujudkan tingkah laku yang lebih efektif (Juliawati, 2014).

Pelaksanaan dalam kegiatan layanan bimbingan kelompok akan menggunakan topik tugas yaitu yang membahas topik-topik yang berkaitan dengan faktor-faktor yang termasuk dalam konformitas teman sebaya. Dengan demikian selama beberapa kali diberikan layanan bimbingan kelompok diharapkan dapat mencegah adanya konformitas teman sebaya dikalangan remaja khususnya di sekolah. Apabila permasalahan tersebut dapat dicegah atau diatasi maka tidak ada lagi masalah yang muncul dikelas $\mathrm{X}$ yang berkaitan dengan konformitas teman sebaya. Sehingga, tujuan dari penelitian ini yaitu (1) untuk mengetahui pemahaman siswa tentang konformitas teman sebaya pada kelompok eksperimen sebelum diberikan perlakuan layanan bimbingan kelompok, (2) untuk mengetahui pemahaman siswa tentang konformitas teman sebaya pada kelompok eksperimen sesudah diberikan perlakuan layanan bimbingan kelompok, (3) untuk mengetahui pengaruh layanan bimbingan kelompok terhadap konformitas teman sebaya pada kelompok yang diberikan perlakuan layanan bimbingan kelompok.

\section{METODE}

Metodologi penelitian ini menggunakan desing eksperimen one group pretest-posttest. Design eksperimen ini dilakukan dengan cara memberikan pretest kepada kelompok eksperimen sebelum perlakuan dilakukan dan setelah perlakuan dilakukan, diberikan posttest guna melihat perbandingan hasil sebelum dengan sesudah perlakuan diberikan (Yusuf, 2013). Penentuan sampel dilakukan dengan purposive sampling dengan subjek penelitian 10 orang siswa, kemudian data penelitian dikumpulkan dengan menggunakan instrumen konformitas 
teman sebaya dengan menggunakan skala likert yang sudah di validasi dengan memperhatikan prosedur pengembangan instrumen penelitian yang baik dan sahih.

Analisis data yang digunakan dalam menjawab pertanyaan penelitian ini menggunakan skor ideal (Azwar, 2010) dan untuk melihat konformitas teman sebaya sebelum dan sesudah diberikan perlakuan dimanfaatkan teknik statistik non parametrik dengan asumsi data yang kurang dari 30 tidak berdistribusi normal. Analisis statistik non parametrik yang dimanfaatkan yaitu uji jenjang bertanda Wilcoxon (signed ranks test) karena peneliti ingin melihat kepastian tentang ada atau tidaknya perbedaan kondisi konformitas teman sebaya setelah perlakuan diberikan (Santoso, S, 2012; Yandri dan Istiqlal, 2017)

\section{HASIL}

Temuan penelitian ini menjelaskan bahwa terdapat pengaruh yang signifikan terhadap konformitas teman sebaya pada siswa setelah diberikan perlakuan layanan bimbingan kelompok. Konfomitas teman sebaya merupakan salah satu pengaruh sosial yang dilakukan oleh remaja yang suka hidup berkelompok, semua individu yang mengikuti suatu kelompok tertentu harus mengikuti semua norma atau peraturan dalam kelompok tersebut, supaya individu tersebut tidak dicela, diremehkan dan dicemooh oleh semua anggota kelompok tersebut. Jika konformitas teman sebaya yang dimunculkan negatif, maka ini akan menimbulkan efek yang buruk pada remaja tersebut. Untuk itu, perlu dilakukan penelitian untuk menjelaskan fenomena konformitas teman sebaya siswa serta perlu adanya penanggulangan yang tepat sehingga konformitas teman sebaya yang negatif tidak terjadi. Asumsi peneliti, konformitas teman sebaya siswa yang negatif bisa dikendalikan dengan memanfaatkan layanan bimbingan kelompok.

Berikut ini dijelaskan gambaran konformitas teman sebaya siswa sebelum dilakukannya perlakuan berupa layanan bimbungan kelompok yang bisa dilihat pada tabel berikut.

Tabel 1. Hasil Pretest Konformitas Teman Sebaya Siswa

\begin{tabular}{cccc}
\hline Kategori & Rentang Skor & Frekuensi & Persentase \\
\hline Sangat Rendah & $\leq 163$ & 3 & 30 \\
\hline Rendah & $163>$ s.d $\leq 173$ & 3 & 30 \\
\hline Sedang & $173>$ s.d $\leq 184$ & 2 & 20 \\
\hline Tinggi & $184>$ s.d $\leq 194$ & 2 & 20 \\
\hline Sangat Tinggi & $194>$ & 0 & 0 \\
\hline \multicolumn{5}{c}{ Jumlah } & 10 & 100 \\
\hline
\end{tabular}


Dari tabel di atas, bisa dijelaskan bahwa kondisi konformitas teman sebaya siswa yang positif berada pada kategori rendah, hal ini dibuktikan dengan hasil rata-rata skor kelompok yaitu 165,2. Hal ini menunjukkan bahwa, masih ada siswa dalam satu kelas yang terpengaruh dengan konformitas teman sebaya yang negatif.

Kemudian, penjelasan gambaran konformitas teman sebaya siswa setelah dilakukannya perlakuan berupa layanan bimbungan kelompok yang bisa dilihat pada tabel berikut

Tabel 2. Hasil Posttest Konformitas Teman Sebaya Siswa

\begin{tabular}{cccc}
\hline Kategori & Rentang Skor & Frekuensi & Persentase \\
\hline Sangat Rendah & $\leq 163$ & 0 & 0 \\
\hline Rendah & $163>$ s.d $\leq 173$ & 0 & 0 \\
\hline Sedang & $173>$ s.d $\leq 184$ & 4 & 40 \\
\hline Tinggi & $184>$ s.d $\leq 194$ & 3 & 30 \\
\hline Sangat Tinggi & $194>$ & 3 & 30 \\
\hline & Jumlah & 10 & 100 \\
\hline
\end{tabular}

Pada tabel 2, bisa dijelaskan bahwa kondisi konformitas teman sebaya siswa yang positif berada pada kategori tinggi, hal ini dibuktikan dengan hasil rata-rata skor kelompok yaitu 193,6. Hal ini menunjukkan bahwa, setelah diberikan perlakuan berupa layanan bimbingan kelompok konformitas teman sebaya siswa menjadi lebih positif.

Hasil penelitian menujukkan bahwa terdapat perbedaan konformitas teman sebaya pada siswa sebelum diberikan perlakuan (Pretest) dan sesudah diberikan perlakuan (Posttest) berupa layanan bimbingan kelompok. Kondisi konformitas teman sebaya siswa pada saat pretest berada pada skor rata-rata 165,2 setelah diberi perlakuan berupa layanan bimbingan kelompok menjadi berada pada skor rata-rata 193,6, sehingga terjadi pengurangan tingkat konformitas teman sebaya sebanyak 17,19\%. Kemudian dari hasil uji statistik non parametik dengan rumus Wilcoxon Signed Rank. Test yang menunjukkan bahwa angka probabilitas Sig (2Tailed) konformitas teman sebaya yang dimiliki siswa sebesar 0,005 atau probabilitas di bawah alpha $0,05(0,005<0,05)$, dari hasil tersebut maka Ho ditolak dan Ha diterima. Dengan demikian, hipotesis yang diuji dalam penelitian dapat diterima yaitu terdapat pengeruh yang signifikan terhadap konformitas teman sebaya pada siswa setelah diberikan perlakuan layanan bimbingan kelompok.

\section{PEMBAHASAN}

Kondisi konformitas teman sebaya siwa sebelum dilakukan layanan bimbingan kelompok menunjukkan bahwa masih ada siswa dalam satu kelas yang terpengaruh dengan 
konformitas teman sebaya yang negatif dengan skor rata-rata yaitu 165,2. Konformitas merupakan bentuk pengaruh sosial dimana individu mengubah sikap dan tingkah lakunya agar sesuai dengan norma sosial. Norma sosial dapat berupa injuctive norms yaitu hal yang seharusnya kita lakukan atau descriptive norms, yaitu apa yang kebanyakan orang lakukan. Injuctive norms biasanya dinyatakan secara eksplisit (tegas), misalnya di dalam sebuah kelompok individu harus menggunakan pakaian tidak rapi. Descriptive norms biasanya bersifat implisit (tidak dinyatakan tegas), misalnya menghormati orang tua dengan bersikap sopan (Baron, Branscombe, dan Byrne dalam Sarwono dan Eko, 2009). Perilaku konformitas muncul ketika individu mengikuti perilaku atau sikap orang lain,dikarenakan oleh tekanan orang lain, baikyang nyata maupun yang dibayangkan (Sumiar \& Miyuntari, 2015.

Seseorang yang konfromitas terhadap kelompoknya jika perilaku individu didasarkan pada harapan kelompok atau masyarakat. Dasar-dasar yang menyebabkannya adalah: 1) Pengaruh sosial normatif. Pengaruh sosial didasarkan pada keingingan individu untuk disukai atau diterima oleh orang lain dan agar terhindar dari penolakan, 2) Pengaruh sosial informasional. Pengaruh sosial yang didasar-kan pada keinginan individu untuk menjadi benar (Baron dan Byrne, 2005). Kemudian, konformitas merupakan suatu tuntutan yang tidak tertulis dari kelompok teman sebaya terhadap anggotanya tetapi memiliki pengaruh yang kuat dan dapat menyebabkan munculnya perilaku-perilaku tertentu pada anggota kelompok (Zebua dan Nurdjayadi, 2001). Disamping itu, remaja dengan kontrol diri tinggi mampu mengarahkan dan mengatur perilakunya menuju ke arah konsekuensi positif, sehingga mahasiswa dengan kontrol diri yang tinggi mampu mengatur stimulus sehingga dapat menyesuaikan perilakunya kepada hal-hal yang positif (Susanti dan Nurwidawati, 2014).

Kemudian setelah diberikan perlakuan berupa layanan bimbingan kelompok, konformitas teman sebaya siswa menjadi lebih positif dengan skor rata-rata 193,6 dan dari hasil uji Wilcoxon Signed Rank Test yang menunjukkan bahwa angka probabilitas Sig (2- Tailed) konformitas teman sebaya yang dimiliki siswa sebesar 0,005 atau probabilitas di bawah alpha 0,05 , hal ini berarti terdapat pengeruh yang signifikan terhadap konformitas teman sebaya pada siswa setelah diberikan perlakuan layanan bimbingan kelompok.. Penurunan Tingkat konformitas pada remaja bisa terjadi karena perkembangan pemahaman remaja sehingga mereka dapat memberikan keputusan tanpa takut ditolak oleh kelompok (Susanti dan Nurwidawati, 2014). Pemberian perlakuan yang tempat terhadap seseorang yang konfomitas terhadap kelompoknya, bisa saja merubah pemehamannya, sehingga tidak terlalu berpengaruh pada remaja. Hal ini bisa dilihat dari perlakuan berupa layanan bimbingan kelompok, dimana layanan bimbingan kelompok mampu menurunkan tingkat konformitas negatif remaja. 
Layanan bimbingan kelompok dapat mendorong pengembangan nilai rasa, pemikiran, persepsi, wawasan dan pengetahuan, dan serta sikap untuk mewujudkan tingkah laku yang lebih efektif (Juliawati, 2014). Selain itu, layanan bimbingan kelompok juga cukup efektif untuk meningkat solidaritas siswa dalam menolong teman (Sitompul, 2015).

\section{SIMPULAN}

Simpulan hasil penelitian yang telah dilakukan yaitu (1) gambaran konformitas teman sebaya sebelum diberi perlakuan berada pada kategori rendah, (2) gambaran konformitas teman sebaya setelah diberi perlakuan berada pada kategori tinggi, (3) terdapat pengaruh yang signifikan terhadap konformitas teman sebaya pada siswa setelah diberikan perlakuan layanan bimbingan kelompok. Dari hasil penelitian ini disarankan kepada guru BK untuk meningkatkan pelaksanaan kegiatan layanan bimbingan kelompok di sekolah, kepada siswa agar meningkatkan keterampilan sosial dalam kehidupan sehari-hari dan tetap melaksanakan kegiatan layanan bimbingan kelompok serta kepada peneliti selanjutnya agar melakukan penelitian serupa dengan memanfaatkan layanan bimbingan konseling yang lainnya.

\section{REFERENSI}

Ali, M \& Asrori, M. (2014). Psikologi Remaja Perkembangan Peserta Didik. Jakarta : Bumi Aksara Azwar, S. (2010). Penyusunan Skala Psikologi. Yogyakarta: Pustaka Pelajar.

Baron, R.A., dan Bryne, D. (2005). Psikologi Sosial Jilid 2 (Terjemahan: Djuwita, R. dkk). Jakarta: Erlangga

Elida. (2006). Psikologi Perkembangan Remaja. Padang: Angkasa Raya.

Juliawati, D. (2014). Efektivitas Layanan Bimbingan Kelompok Mengurangi Prokrastinasi Akademik Siswa. International Guidance and Counseling Conferrence, At Padang, West Sumatera, Indonesia. From https://wnw.researchgate.net/publication/327915616_ EFEKTIVITAS_LAYANAN_BIMBINGAN_KELOMPOK_MENGURANGI_ PROKRASTINASI_AKADEMIK_SISWA

Mayara, B. H., Yuniarrahmah E., \& Mayangsari, M, D. (2016). Hubungan Kepercayaan Diri dengan Konformitas pada Remaja. Jurnal Ecopsy. 3 (2).

Novianti, L \& Putra, D. (2014). Hubungan Antara Konformitas terhadap Teman Sebaya dengan Perilaku Bullying pada Siswa 22 Tanggerang. Jurnal Neotic Psichology. 4 (1). 85.

Rahmayanthi, R. (2017). Konformitas Teman Sebaya dalam Perspektif Multikultural, Journal of Multicultural Studies in Guidance and Conseling, 1(1). 71-72. 
Santoso, S. (2012). Aplikasi SPSS pada Statistik Nonparametrik. Jakarta: Alex Media Komputindo

Sarwono, S, W., \& Eko, A, M. (2011). Psikologi Sosial. Jakarta : Salemba Humika

Sear, D,O., \& Jonathan, L, F. (1985). Psikologi Sosial, Erlangga : Gelora Aksara Pratama

Sitompul, D. N. (2015). Pengaruh Penerapan Layanan Bimbingan Kelompok Teknik RolePlaying terhadap Perilaku Solidaritas Siswa dalam Menolong Teman di SMA Negeri 1 Rantau Utara T.A 2014/2015, Jurnal Edutech, 1 (1)

Suminar, E \& Miyuntari, T. (2015). Konsep Diri, Konformitas dan Perilaku Konsumtif pada Remaja. Persona, Jurnal Psikologi Indonesia. 4 (2).

Susanti, E \& Nurwidawati, D. (2014). Hubungan Antara Kontrol Diri dan Konformitas dengan Prokrastinasi Akademik pada Mahasiswa Program Studi Psikologi UNESA. Jurnal Character. 2 (3).

Tohirin, 2011. Bimbingan dan Konseling di Sekolah dan Madrasah (Berbasis Integrasi). Jakarta : Raja Grafindo Persada

Yandri, H., \& Istiqlal, A. (2017). Efektivitas Dirasah Pengembangan Diri Melalui Pelayanan Konseling dalam Membentuk Kecerdasan Emosi Mahasantri Ma'had Al Jami’ah IAIN Kerinci. Jurnal Tarbawi, 13 (01).

Yusuf, A. M. (2013). Metodologi Penelitian: Kualitatif, Kuantitatif, dan Penelitian Gabungan. Padang : UNP Press.

Zebua, A., \& Nurdjayadi. (2001). Hubungan antara Konformitas dan Konsep Diri dengan Perilaku Konsumtif pada Remaja Putri. Jurnal Phronesis, 3 (6). 